\title{
Utilisation of front-face fluorescence spectroscopy for the determination of some selected chemical parameters in soft cheeses
}

\author{
Romdhane KAROUI ${ }^{a *}$, Abdul Mounem MOUAZENa, Eric DUFOUR ${ }^{\mathrm{b}}$, \\ Robert SCHOONHEYDTc, Josse DE BAERDEMAEKER ${ }^{\mathrm{a}}$ \\ a Division of Mechatronics, Biostatistics and Sensors (MeBioS), Department of Biosystems, \\ K.U. Leuven, Kasteelpark Arenberg 30, 3001, Leuven, Belgium \\ b U.R. "Typicité des Produits Alimentaires", ENITA de Clermont-Ferrand, BP 35, \\ 63370 Lempdes, France \\ c Centre for Surface Chemistry and Catalysis, K.U. Leuven, Kasteelpark Arenberg 23, \\ 3001 Leuven, Belgium
}

Received 16 August 2005 - Accepted 21 November 2005

\begin{abstract}
This study evaluated the usefulness of front-face fluorescence spectroscopy for predicting some selected chemical parameters in soft cheeses in external (E) and central (C) zones. Fat, dry matter (DM), pH, total nitrogen (TN) and water-soluble nitrogen (WSN) contents were determined by reference methods. Tryptophan (excitation: $290 \mathrm{~nm}$; emission: 305-450 nm), riboflavin (excitation: $380 \mathrm{~nm}$; emission: 400-640 nm) and vitamin A fluorescence spectra (emission: $410 \mathrm{~nm}$; excitation: $270-350 \mathrm{~nm}$ ) were recorded on the investigated cheeses. Three separate prediction models were developed from the tryptophan, riboflavin and vitamin A spectra using partial least squares (PLS) regression and the leave-one-out cross-validation technique. The results showed that fat, DM, fat in dry matter and WSN were the best predicted with the vitamin A fluorescence spectra models providing the highest values of the determination coefficient $\left(R^{2}\right)$ of $0.88,0.86,0.86$ and 0.84 , respectively. The prediction of the $\mathrm{pH}$ was also successful using riboflavin fluorescence spec$\operatorname{tra}\left(R^{2}=0.85\right)$. The WSN/TN ratio can also be predicted from the three intrinsic probes, but with much lower precision.
\end{abstract}

soft cheese / tryptophan / riboflavin / vitamin A / partial least squares regression

摘要 - 苂光光谱法测定软质干酪的化学参数。本文评价荧光光谱法预测软质干酪表面和中 心些化学参数的准确性。首先用参考方法测定干酪中脂肪、干物质、 $\mathrm{pH}$ 、总氮和水溶性 氮。干酪中色氨酸 (激发波长 ex: $290 \mathrm{~nm}$, 发射波长 $\mathrm{em}: 305 \sim 450 \mathrm{~nm}$ ), 核黄素 (ex: $380 \mathrm{~nm}$, $\mathrm{em}$ : $400 \sim 640 \mathrm{~nm})$, 维生素 $\mathrm{A}(\mathrm{ex}: 270 \sim 350 \mathrm{~nm}, \mathrm{em}: 410 \mathrm{~nm}) 3$ 种化合物的荧光检测波长已有文 献报道。在相应的激发波长和发射波长下记录色氨酸、核黄素和维生素 $\mathrm{A}$ 的苂光光谱, 采 用偏最小二乘法 (PLS) 分别建立 3 个化合物的预测模型, 用留一法交互验证技术验证模型 的有效性。试验结果表明, 用维生素 A 荧光光谱数据建立的模型来可以很好地预测干酪中 脂肪、干物质、干物质中的脂肪和水溶性氮的含量, 四种参数的相关系数 $\left(\mathrm{R}^{2}\right)$ 分别为 0.88 、 0.86、0.86 和 0.84 。用核黄素的荧光光谱模型可以很好地预测干酪 $\mathrm{pH}$ 值的变化（结果也是 也非常满意） $\left(\mathrm{R}^{2}=0.85\right)$ 。用这 3 个模型都可以预测干酪中水溶性氮占总氮的比率 (WSN/ $\mathrm{TN}$ ), 但是预测结果的准确性较差。

软质干酪 / 色氨酸 / 核黄素 / 维生素 A / 偏最小二乘法

* Corresponding author ( 通讯作者): Romdhane.Karoui@biw.kuleuven.be 
Résumé - Utilisation de la spectroscopie de fluorescence frontale pour la détermination de quelques paramètres chimiques à la surface et au centre des fromages à pâte molle. L'objectif de cette étude était d'évaluer le potentiel de la spectroscopie de fluorescence frontale à prédire quelques paramètres chimiques, à la surface et au centre, des fromages à pâte molle. Les teneurs en matière grasse, extrait sec, $\mathrm{pH}$, azote total et en azote soluble ont été déterminées par des méthodes de référence. Des spectres de fluorescence des tryptophanes (excitation : $290 \mathrm{~nm}$; émission: 305$450 \mathrm{~nm}$ ), de la riboflavine (excitation : $380 \mathrm{~nm}$; émission : $400-640 \mathrm{~nm}$ ) et de la vitamine A (émission : $410 \mathrm{~nm}$; excitation : 270-350 nm) ont été également enregistrés sur ces fromages. Trois modèles séparés de prédictions ont été développés à partir des spectres des tryptophanes, de la riboflavine et de la vitamine A en utilisant la technique des moindres carrés partiels avec validation croisée. Les résultats obtenus ont montré que les teneurs en matière grasse, extrait sec, gras sur sec et en azote soluble étaient mieux prédites avec les modèles des spectres de fluorescence de la vitamine A qui donnaient les valeurs les plus élevées du coefficient de détermination $\left(R^{2}\right): 0,88,0,86,0,86$ et 0,84 , respectivement. La prédiction du $\mathrm{pH}$ est réalisée avec succès en utilisant les spectres de fluorescence de la riboflavine $\left(R^{2}=0,85\right)$. Le rapport azote soluble/azote total peut, également, être prédit à partir des trois sondes intrinsèques, mais avec une précision beaucoup plus faible.

fromage à pâte molle / tryptophane / riboflavine / vitamine A / moindres carrés partiels

\section{INTRODUCTION}

Nowadays, the dairy industry has come under increasing pressure to deliver products of high and constant quality into the market place [12]. Thus, a large number of analyses during the manufacturing of foodstuffs, such as cheeses, is demanded. However, food quality can be difficult to assess, because the complex composition of food complicates quantitative and qualitative determination of the individual constituents. When chemical methods are used, destruction of the food matrix is usually necessary prior to measurements in order to isolate the compound of interest. The destruction step is problematic, because it is laborious, it often requires a large amount of chemical reagents, and information is lost when the individual food components are removed from their context. Although a relatively rapid technique (approximately $2 \mathrm{~h}$ after the preparation of cheese samples) has been developed in the last few years, based on trinitrobenze-sulphonic acid (TNBS) $[21,43]$, it is still very expensive, unlike the case of the spectroscopic technique. TNBS reacts specifically with primary amino groups to form a chromophore with a maximum absorbance at $340 \mathrm{~nm}$. The TNBS can be used to determine total free amino acids in cheeses and/or to estimate amino acid concentrations in cheese [21,43]. With spectroscopy, it is possible to measure in a non-invasive way, allowing the individual food components to be assessed simultaneously on-line in the food matrix. These spectroscopic techniques are characterised as quick, cheap after the capital cost is excluded and do not require skilled operators, which is of great importance for the users. They are considered as sensitive, non-destructive, rapid and environmentally friendly, which makes them suitable for online or in-line process control.

The near-infrared (NIR) [1-4, 7, 11, 20, $32,33,41,42,48]$, and mid-infrared (MIR) $[8,16,36]$ spectroscopy techniques have been used for the determination of some chemical parameters (e.g., $\mathrm{pH}$, moisture, protein, fat, etc.) in milk and dairy products for a long time.

Front-face fluorescence spectroscopy is considered as a sensitive technique. The presence of fluorophors in the form of aromatic amino acids, vitamins, cofactors and a variety of flavouring compounds makes it a valuable technique. The application of autofluorescence in analysis of food has increased during the last decade, probably due to the propagated use of chemometrics. In addition, fluorescence spectroscopy offers several inherent advantages for the characterisation of molecular interactions and reactions. First, it is 100-1000 times more sensitive than other spectrophotometric techniques [44]. Second, fluorescent compounds are extremely sensitive to their environments [13]. This environmental 
sensitivity enables characterisation of conformational changes such as those attributable to the thermal, solvent or surface denaturation of proteins, as well as the interactions of proteins with other components. It has been shown that front-face fluorescence spectroscopy can discriminate milk samples subjected to heat treatment from those subjected to homogenisation [13]. It can also be used to monitor structural changes in milk coagulation $[14,17$, $18]$ and cheese manufacture [19, 34, 35]. This technique has also been used to determine the effect of both light and modified atmosphere packaging on the oxidation of dairy products during storage $[9,37-39,49$, 50]. Indeed, Wold et al. [49] have reported that fluorescence properties of riboflavin can be used to measure the degree of degradation of this molecule in dairy products. Finally, front-face spectroscopy has been utilised to determine the geographic origin of milk [28], PDO Gruyère and L'Etivaz PDO cheeses [15, 26] and Emmental cheeses from different European geographic origins, manufactured during winter and summer periods [24, 25, 27].

Only a few papers have been published on the ability of front-face fluorescence spectroscopy to predict some parameters in dairy products. Indeed, Christensen et al. [10] have used this method to predict riboflavin content of 42 yogurt samples, obtaining successful results and underlining the potential of the method to be utilised for rapid determination of riboflavin. This technique has also been used for the determination of lactulose and furosine in milks [30]. However, no research has investigated the feasibility of using front-face fluorescence spectroscopy to predict chemical parameters in cheese.

The purpose of this work was to examine the accuracy of front-face fluorescence spectroscopy for the determination of some selected chemical parameters collected from the external and central zones of 15 soft cheeses produced using three different manufacturing processes. An optimal model for a given chemical parameter (fat, dry matter (DM), $\mathrm{pH}$, total nitrogen (TN), water-soluble nitrogen (WSN) and WSN/ TN ratio) was established by using the tryp- tophan, vitamin A and riboflavin fluorescence spectra.

\section{MATERIALS AND METHODS}

\subsection{Cheese samples}

Among fifteen different soft cheeses, ten traditional (M1, $n=5$ and M2, $n=5$ ) and five stabilised (M3, $n=5$ ) were purchased from a local supermarket. These cheeses were manufactured using different mesophilic starter cultures and they were of the white-mould acid-curd type [17, 19]. A classical cheese-making procedure was used to manufacture soft cheeses. The composition of raw milks was adjusted with cream or skim milk in order to obtain the desired fat-protein ratio. M1 and M2 are cheeses of circular shape, with a thin white coat and ivory ripples, which develops a smooth and creamy texture. Both M1 and M2 cheeses were manufactured from raw milk. M1 differed from M2 in the starters used during the cheese-making procedure. The M3 is a soft-white cheese manufactured from pasteurised milk, with an oval shape and a smooth, velvety, pure penicillin rind. The M3 cheese differed from M1 and M2 cheeses in the cheese-making procedure and the starter cultures used. The cheese-making procedure of the investigated cheeses was similar to that described by Kulmyrzeav et al. [31].

\subsection{Physico-chemical analysis}

The determination of $\mathrm{pH}$, DM, fat content, TN and WSN was as described by Bouton et al. [6]. These parameters were determined on the external (E) zone after removing the primary surface of mould growth forming a thin, grey-white and feltlike rind, and on the central (C) zone $(4 \mathrm{~cm}$ from the rind) for the 15 commercial cheeses. All the analyses were made in duplicate.

\subsection{Fluorescence spectroscopy}

Fluorescence spectra were recorded using a Fluorolog-2 spectrofluorimeter (Spex-Jobin Yvon, Horiba, The Netherlands) 
Table I. Sample statistics of calibration used for the PLS-cross-validation models ${ }^{\text {. }}$

\begin{tabular}{lcccc}
\hline Compositional parameter & Minimum & Maximum & Mean & Standard deviation \\
\hline $\mathrm{pH}$ & 6.11 & 7.46 & 6.85 & 0.39 \\
Fat $\left(\mathrm{g} \cdot 100 \mathrm{~g} \mathrm{~g}^{-1}\right)$ & 22.25 & 36.5 & 26.91 & 25.19 \\
$\mathrm{DM}\left(\mathrm{g} \cdot 100 \mathrm{~g}^{-1}\right)$ & 43.61 & 50.86 & 46.73 & 2.27 \\
Fat in DM & 49.62 & 71.77 & 56.69 & 8.28 \\
TN $\left(\mathrm{g} \cdot 100 \mathrm{~g}^{-1}\right)$ & 2.34 & 3.50 & 3.07 & 0.37 \\
WSN $\left(\mathrm{g} \cdot 100 \mathrm{~g}^{-1}\right)$ & 2.22 & 3.32 & 2.83 & 0.38 \\
WSN/TN & 0.85 & 1.00 & 0.92 & 0.03
\end{tabular}

a Abbreviation: DM, dry matter; TN, total nitrogen; WSN, water-soluble nitrogen.

mounted with a variable angle front-surface accessory. The incidence angle of the excitation radiation was set at $52^{\circ}$ to ensure that reflected light, scattered radiation and depolarisation phenomena were minimised. The emission spectra of the tryptophan residues (305-450 nm; resolution $1 \mathrm{~nm}$; slit widths were set at 1.7 and $1.7 \mathrm{~nm}$ for excitation and emission, respectively) and riboflavin (400-640 nm; resolution: $1 \mathrm{~nm}$; slit widths were set at 2.2 and $2.2 \mathrm{~nm}$ for excitation and emission, respectively) were recorded with the excitation wavelengths set at $290 \mathrm{~nm}$ and $380 \mathrm{~nm}$, respectively. The excitation spectra of vitamin A (270-350 nm; resolution: $1 \mathrm{~nm}$; slit widths were set at 2.2 and $2 \mathrm{~nm}$ for excitation and emission, respectively) were recorded with the emission wavelength set at $410 \mathrm{~nm}$. All spectra were corrected for instrumental distortions in excitation using a rhodamine cell as a reference channel. For each cheese sample (2-cm long, $1-\mathrm{cm}$ wide and $0.5-\mathrm{cm}$ thick), three spectra were recorded.

\subsection{Mathematical treatment of data}

\subsubsection{Processing of spectra}

To reduce the scattering effect, the tryptophan, riboflavin and vitamin A fluorescence spectra were first normalised by reducing the area under each curve to unity as described by Bertrand and Scotter [5]. Mainly the shift of the maximum and the width changes of the spectra were considered following this normalisation.

\subsubsection{Model establishment}

The objective of this task was to build a statistical model between the processed spectra and cheese properties. Several statistical modelling techniques can be adopted for proper calibration performance, such as linear and nonlinear multiple regression analyses, principal component regression (PCR) and partial least squares analysis (PLS). PLS was used in this study for relating the variations in one-response variables $(\mathrm{pH}$, fat, $\mathrm{DM}$, fat in $\mathrm{DM}, \mathrm{TN}$, WSN or WSN/TN ratio) to the variations of several predictors (wavelengths). The spectral measurements recorded were used for the establishment of the PLS statistical models. Three separate models for each element were developed utilising the tryptophan, riboflavin and vitamin A fluorescence spectra. As the number of observations was small (15 cheeses), the regression models were validated by a leave-one-out crossvalidation (Tab. I). This cross-validation enables the dimensions of the predictive model to be chosen. PLS was performed using Unscrambler ${ }^{\circledR}$ software (version 7.8, Camo process AS, Norway).

The practical utility of the calibrations was assessed using the range error ratio (RER) [46]. This ratio is calculated by dividing the range of a given constituent by the prediction error for that constituent and, while susceptible to the presence of extreme values at both ends of the range, it is a useful indicator of the practical utility of a predictive model. 


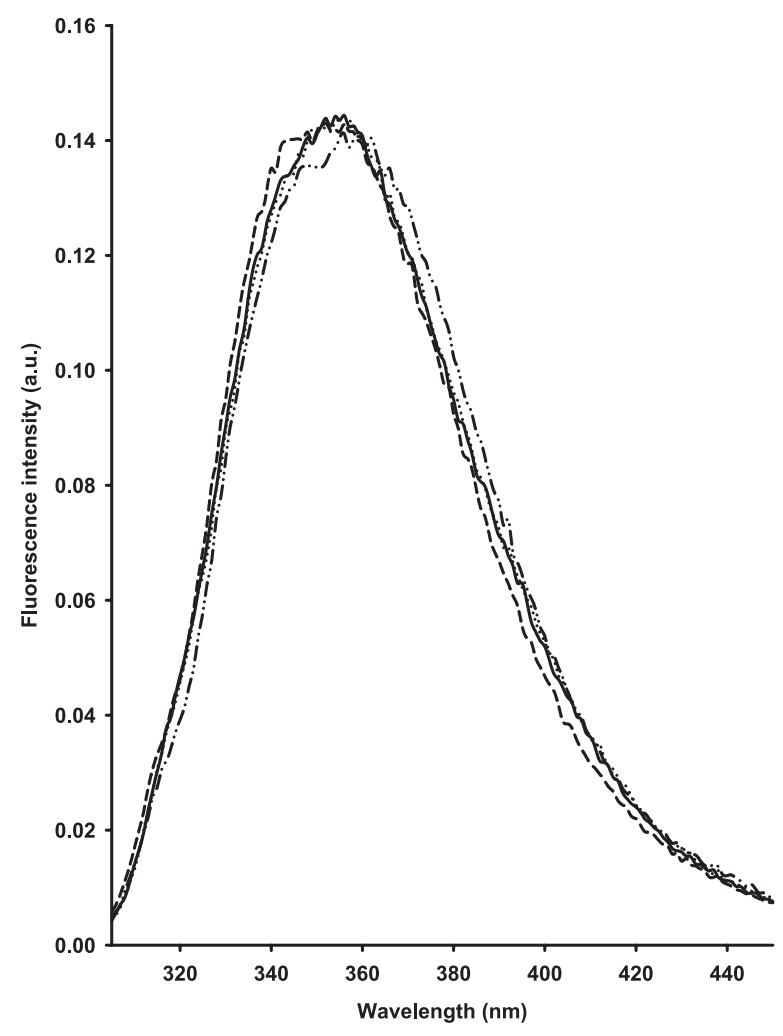

Figure 1. Normalised fluorescence spectra of tryptophan recorded following excitation at $290 \mathrm{~nm}$ in the central zone of M2 (-), external zone of M2 (...), central zone of M3 (- - -) and external zone of M3 (-..-..-) cheeses.

\section{RESULTS AND DISCUSSION}

\subsection{Fluorescence spectra of different cheese varieties}

Recording of fluorescence spectra at different excitation and emission wavelengths was performed to study the differences between the 3 cheese varieties in both the $\mathrm{E}$ and $\mathrm{C}$ zones. Tryptophan, riboflavin and vitamin A fluorescence spectra recorded on the investigated cheeses in the $\mathrm{E}$ and $\mathrm{C}$ zones are shown in Figures 1, 2 and 3, respectively. As most of the spectra show very similar shapes and it can therefore be very difficult to make visual discrimination, only the $\mathrm{E}$ and $\mathrm{C}$ zones of M2 and M3 cheese samples are shown in the figures.

Considering tryptophan fluorescence spectra (Fig. 1), the normalised emission spectra of M2 cheeses exhibited a maximum at about $350 \mathrm{~nm}$ for both the $\mathrm{C}$ and $\mathrm{E}$ zones, while M3 cheese samples had a maximum at $350 \mathrm{~nm}$ for the samples of the $\mathrm{C}$ zone and another maximum located at $355 \mathrm{~nm}$ for the samples of the E zone (Fig. 1). In addition, the width of fluorescence spectra of $\mathrm{M} 3$ cheeses was larger for the E zone than for the $\mathrm{C}$ zone cheese samples, which was not the case of the M2 cheese samples. This indicates a higher diversity for the environment of tryptophan residues between the $\mathrm{E}$ and $\mathrm{C}$ zones of the M3 cheeses. Similar results to those obtained with the $\mathrm{M} 2$ cheese samples were observed for the M1 cheese samples (data not shown).

At the excitation wavelength of $380 \mathrm{~nm}$ (Fig. 2), the spectra of M2 cheeses again showed a slight difference between the $\mathrm{E}$ and $\mathrm{C}$ zones, whereas EM3 and CM3 cheese samples exhibited a large difference. In addition, the shape of the spectra changes according to the cheese variety. 


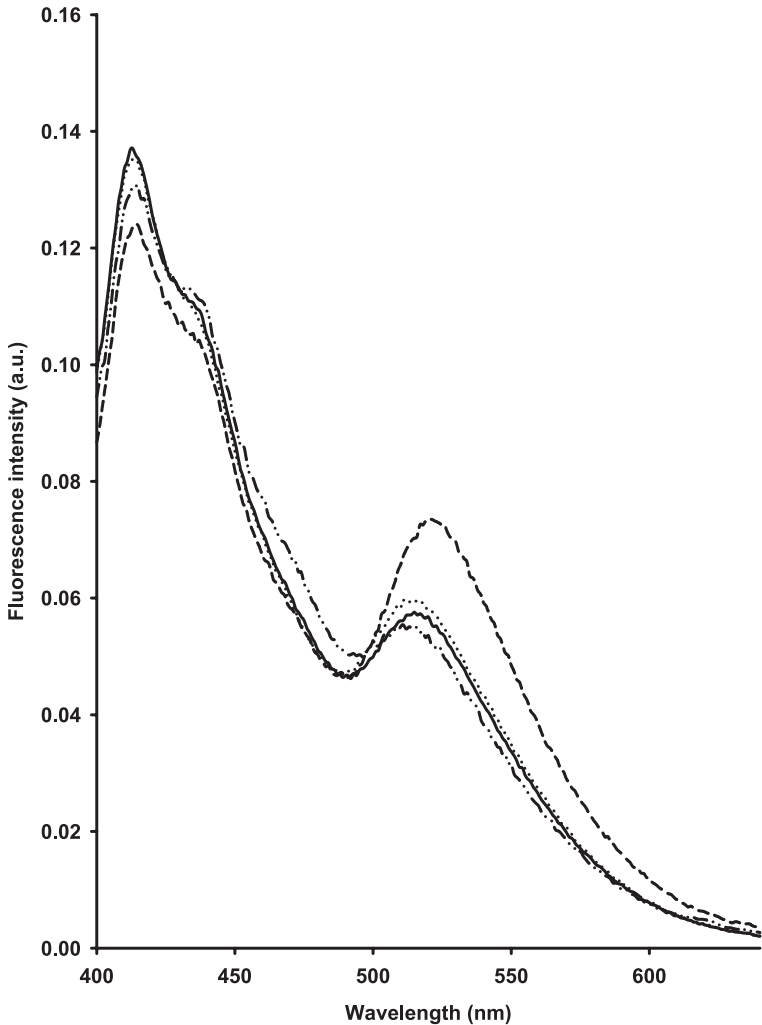

Figure 2. Normalised fluorescence spectra of riboflavin recorded following excitation at $380 \mathrm{~nm}$ in the central zone of M2 (-), external zone of M2 (...), central zone of M3 (- - -) and external zone of M3 (-..-..-) cheeses.
When the excitation spectra were scanned from 280 to $350 \mathrm{~nm}$ with emission measured at $410 \mathrm{~nm}$, two maxima located at 305 and $322 \mathrm{~nm}$ and a shoulder at $295 \mathrm{~nm}$ (Fig. 3) were observed. The shape of the spectra changes with the manufacturing process of the investigated cheeses. Recently, it has been reported that the shape of the vitamin A excitation spectrum is correlated with the physical state of the triglycerides in the fat globules [14, 22, 23]. Considering the short distance between tryptophan residues and vitamin $\mathrm{A}$ in the cheese matrix, fluorescence transfer between a donor (tryptophan) and an acceptor may be observed. After excitation at $290 \mathrm{~nm}$, photons emitted by tryptophan residues are absorbed by the second probe (vitamin A) fluorescing with maximum excitation at about $322 \mathrm{~nm}$ (Fig. 3). It is concluded that a spectrum recorded on a cheese sample between 305 and $450 \mathrm{~nm}$ following excita- tion at $290 \mathrm{~nm}$ contains information on protein structure (denaturation), as well as on protein-lipid interactions.

The emission and excitation spectra shown in Figures 1-3 are due to numerous fluorescent compounds occurring in the various cheese samples in different concentrations and in different environments, leading to various forms of these spectra. As the number of wavelengths in the tryptophan, riboflavin and vitamin A fluorescence spectra were much larger than the number of cheese samples, it was necessary to use chemometric tools to extract information from the data set.

\subsection{Partial least squares analysis}

Running the PLS analysis together with the leave-one-out cross-validation technique provided different calibration results according to the chemical parameters of the 


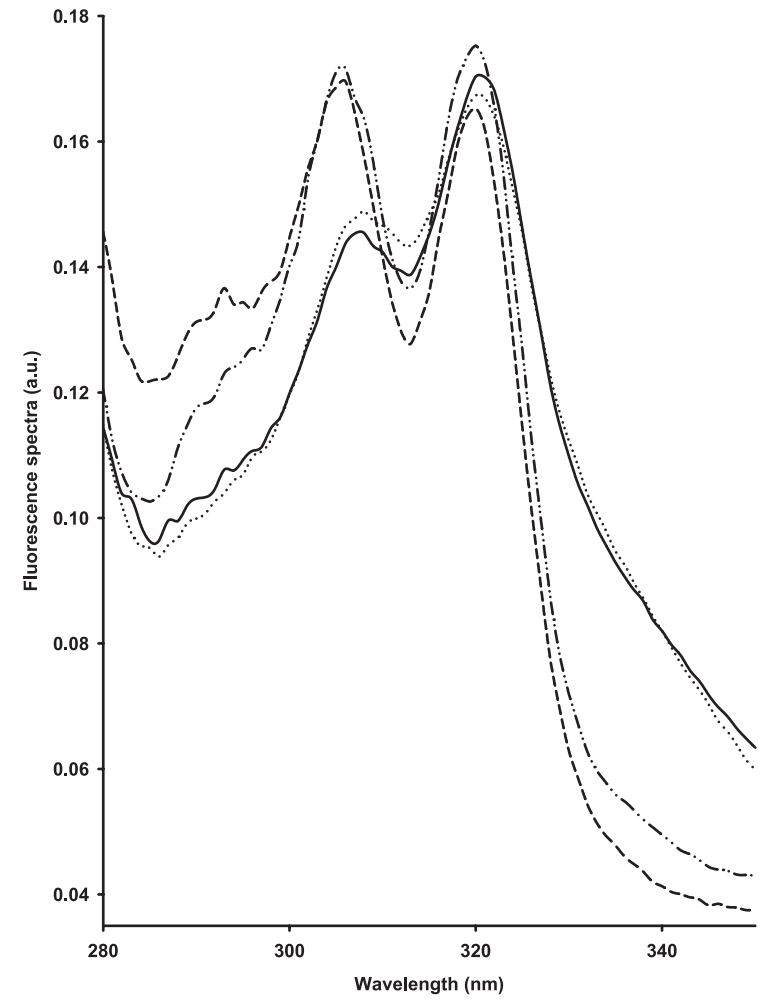

Figure 3. Normalised fluorescence spectra of vitamin A recorded following emission at $410 \mathrm{~nm}$ in the central zone of M2 (-), external zone of M2 (..), central zone of M3 (- - -) and external zone of M3 (-..-..-) cheeses. cheeses. In order to compare between the different established models for a given parameter, the values of the root mean square error of prediction (RMSEP) of the calibration set were considered. The accuracy of each calibration can be evaluated based on the coefficients of determination, $R^{2}$, for predicted versus measured compositions in cross-validation and the ratio of standard deviation of the data set (SD) to RMSEP. In fact, $R^{2}$ indicates the percentage of the variance in the $Y$ variable that is accounted for by the $X$ variable. A value for $R^{2}$ between 0.50 and 0.65 indicates that more than $50 \%$ of the variance in $Y$ is accounted for by the variable $X$, so that discrimination between high and low concentrations can be made. A value for $R^{2}$ between 0.66 and 0.81 indicates approximate quantitative predictions, whereas a value for $R^{2}$ between 0.82 and 0.90 reveals a good prediction. Calibration models with a value for $R^{2}$ above 0.91 are considered to be excellent [47]. The ratio of the SD to the RMSEP, called the ratio of prediction to deviation (RPD), is the factor by which the prediction accuracy has been increased compared with using the mean composition for all samples. This ratio is desired to be larger than 2 for a good calibration [40]. A RPD ratio less than 1.5 indicates incorrect predictions and the model cannot be used for further prediction.

Table II shows the results of PLS. For all investigated parameters, the optimum number of latent variables (LV) or PLS components used in the model ranged from 4 to 7 . Using the tryptophan fluorescence spectra, the measurements of fat $\left(R^{2}=0.71\right.$; $\mathrm{RPD}=1.86$; RER = 5.12) (Fig. 4a), DM $\left(R^{2}=0.68 ;\right.$ RPD = 1.79; RER = 5.72) (Fig. 4b), fat in $\mathrm{DM}\left(R^{2}=0.71 ; \mathrm{RPD}=1.86\right.$; RER $=$ 4.97), $\mathrm{TN}\left(R^{2}=0.73 ; \mathrm{RPD}=1.93 ; \mathrm{RER}=6.04\right)$ (Fig. $4 \mathrm{c})$ and $\mathrm{WSN}\left(R^{2}=0.81 ; \mathrm{RPD}=2.34\right.$; 
Table II. Validation results of tryptophan, riboflavin and vitamin A models developed with the PLS-cross-validation regression technique.

\begin{tabular}{|c|c|c|c|c|c|c|c|}
\hline $\begin{array}{l}\text { Compositional } \\
\text { parameter }\end{array}$ & Spectrum & LV & $R^{2}$ & Slope & RMSEP & RPD & RER \\
\hline \multirow{3}{*}{$\mathrm{pH}$} & Tryptophan & 4 & 0.64 & 0.68 & 0.23 & 1.66 & 5.76 \\
\hline & Riboflavin & 4 & 0.85 & 0.86 & 0.15 & 2.58 & 8.92 \\
\hline & Vitamin A & 6 & 0.76 & 0.78 & 0.19 & 2.03 & 7.03 \\
\hline \multirow{3}{*}{ Fat $\left(\mathrm{g} \cdot 100 \mathrm{~g}^{-1}\right)$} & Tryptophan & 4 & 0.71 & 0.73 & 2.79 & 1.86 & 5.12 \\
\hline & Riboflavin & 5 & 0.84 & 0.85 & 2.04 & 2.55 & 6.99 \\
\hline & Vitamin A & 6 & 0.88 & 0.89 & 1.81 & 2.86 & 7.86 \\
\hline \multirow{3}{*}{$\mathrm{DM}\left(\mathrm{g} \cdot 100 \mathrm{~g}^{-1}\right)$} & Tryptophan & 4 & 0.68 & 0.73 & 1.27 & 1.79 & 5.72 \\
\hline & Riboflavin & 5 & 0.82 & 0.83 & 0.97 & 2.35 & 7.49 \\
\hline & Vitamin A & 6 & 0.86 & 0.88 & 0.85 & 2.66 & 8.51 \\
\hline \multirow{3}{*}{ Fat in DM $\left(\mathrm{g} \cdot 100 \mathrm{~g}^{-1}\right)$} & Tryptophan & 4 & 0.71 & 0.73 & 4.45 & 1.86 & 4.97 \\
\hline & Riboflavin & 5 & 0.84 & 0.84 & 3.28 & 2.53 & 6.75 \\
\hline & Vitamin A & 6 & 0.86 & 0.88 & 3.07 & 2.70 & 7.21 \\
\hline \multirow{3}{*}{$\mathrm{TN}\left(\mathrm{g} \cdot 100 \mathrm{~g}^{-1}\right)$} & Tryptophan & 4 & 0.73 & 0.74 & 0.19 & 1.93 & 6.04 \\
\hline & Riboflavin & 5 & 0.80 & 0.80 & 0.17 & 2.22 & 6.97 \\
\hline & Vitamin A & 6 & 0.81 & 0.84 & 0.16 & 2.28 & 7.18 \\
\hline \multirow{3}{*}{ WSN $\left(g \cdot 100 g^{-1}\right)$} & Tryptophan & 4 & 0.81 & 0.82 & 0.16 & 2.34 & 6.78 \\
\hline & Riboflavin & 5 & 0.82 & 0.82 & 0.16 & 2.42 & 7.00 \\
\hline & Vitamin A & 6 & 0.84 & 0.87 & 0.15 & 2.58 & 7.47 \\
\hline \multirow{3}{*}{ WSN/TN $\left(\mathrm{g} \cdot 100 \mathrm{~g}^{-1}\right)$} & Tryptophan & 4 & 0.48 & 0.55 & 0.02 & 1.38 & 6.9 \\
\hline & Riboflavin & 7 & 0.52 & 0.62 & 0.02 & 1.44 & 7.18 \\
\hline & Vitamin A & 3 & 0.52 & 0.55 & 0.02 & 1.45 & 7.23 \\
\hline
\end{tabular}

a Abbreviations: DM, dry matter; TN, total nitrogen; WSN, water-soluble nitrogen; LV, latent variables; $R^{2}$, determination coefficient; RMSEP, root mean square error of prediction; RPD, ratio of prediction deviation (Standard deviation/RMSEP); RER, range error ratio (maximum-minimum/RMSEP).

RER $=6.78$ ) can be considered as approximate, while measurement of $\mathrm{pH}\left(R^{2}=0.64\right.$; $\mathrm{RPD}=1.66$; $\mathrm{RER}=5.76$ ) could be used only for differentiating between high and low values. Unsuccessful prediction of the $\mathrm{WSN} / \mathrm{TN}$ ratio $\left(R^{2}=0.48 ; \mathrm{RPD}=1.38\right.$; $\mathrm{RER}=6.9$ ) was observed.

Considering riboflavin fluorescence spectra, better results were obtained. Indeed, measurements of $\mathrm{pH}\left(R^{2}=0.85\right.$; $\mathrm{RPD}=2.58 ; \mathrm{RER}=8.92)$, fat $\left(R^{2}=0.84\right.$; $\mathrm{RPD}=2.55 ; \mathrm{RER}=6.99), \mathrm{DM}\left(R^{2}=0.82\right.$; $\mathrm{RPD}=2.35 ; \mathrm{RER}=7.49)$, fat in $\mathrm{DM}\left(R^{2}=\right.$ $0.84 ; \mathrm{RPD}=2.53 ; \mathrm{RER}=6.75)$ and $\mathrm{WSN}$ $\left(R^{2}=0.82 ; \mathrm{RPD}=2.42 ; \mathrm{RER}=7.00\right)$ could be evaluated as good, while measurement of TN $\left(R^{2}=0.80 ; \mathrm{RPD}=2.22 ; \mathrm{RER}=6.97\right)$ was considered as approximate. Regarding the WSN/TN ratio, similar results to those obtained with tryptophan fluorescence spectra were also found with riboflavin fluorescence spectra $\left(R^{2}=0.52 ; \mathrm{RPD}=1.44\right.$; RER = 7.18).

Finally, regarding vitamin A fluorescence spectra, measurements of fat $\left(R^{2}=\right.$ $0.88 ; \mathrm{RPD}=2.86 ; \mathrm{RER}=7.86), \mathrm{DM}\left(R^{2}=\right.$ $0.86 ; \mathrm{RPD}=2.66 ; \mathrm{RER}=8.51)$, fat in $\mathrm{DM}$ $\left(R^{2}=0.86 ; \mathrm{RPD}=2.70 ; \mathrm{RER}=7.21\right)$ and $\mathrm{WSN}\left(R^{2}=0.84 ; \mathrm{RPD}=2.58 ; \mathrm{RER}=7.47\right)$ can be evaluated as good, while measurements of $\mathrm{pH}\left(R^{2}=0.76 ; \mathrm{RPD}=2.03 ; \mathrm{RER}=7.03\right)$ and $\mathrm{TN}\left(R^{2}=0.81 ; \mathrm{RPD}=2.28 ; \mathrm{RER}=\right.$ 7.18) were considered as approximate. Unsuccessful measurement was again 
obtained for the WSN/TN ratio, similar to the tryptophan and riboflavin fluorescence spectra.

Based on the calibration data set, the $\mathrm{pH}$, fat, DM, fat in DM and WSN of the investigated cheeses were the best components to be predicted with the developed riboflavinand vitamin A-PLS methodologies. The three intrinsic probes gave similar results for the prediction of TN and WSN/TN ratios. Although the results obtained for the WSN/TN ratio were not good, those of fat, $\mathrm{DM}$, fat in DM and WSN obtained with both riboflavin and vitamin A fluorescence spectra were of special interest. This provides an alternative method to the reference methods used to determine these parameters, since, for example, the Kjeldahl and the Gerber methods utilised for the determination of protein and fat contents, respectively, are very expensive and require skilled operators. Even though the TNBS method can be considered as relatively rapid, it is very expensive when looking at enzymatic and bio-chemical needs, which is not the case of the fluorescence method when the capital cost is excluded.

However, the results obtained are less successful than those obtained with NIR or MIR used on different cheese varieties. Indeed, it has been reported that NIR can be used successfully to measure the moisture content of Cheddar [45] and Australian cheeses [2] with good accuracy. Furthermore, several other papers have shown that NIR could be a suitable technique for the prediction of fat in semi-hard cheese [48] and in American-style hard cheeses [45]. Wittrup and Nørgaard [48] measured fat $(R=0.99)$, TN $(R=0.98)$ and $\mathrm{DM}$ $(R=0.98)$ contents of 107 semi-hard Danbo cheeses with a degree of success higher than those achieved in this study.

Measurements of WSN and the WSN/ TN ratio determined by fluorescence spectra in the present investigation were less successful than those found with MIR used for the measurement of some chemical parameters in European Emmental cheeses produced during wintertime [29]. However, prediction of TN and fat were more successful with fluorescence spectroscopy than with MIR [29]. Considering the measure- ment of $\mathrm{pH}$, similar results were obtained with riboflavin and MIR [29], while less successful results were obtained with tryptophan and vitamin A. The difference in the results found with NIR and MIR by Karoui et al. [29] and those obtained in the present investigation could arise from the small range of the physico-chemical parameters considered in the present investigation (Tab. I).

A number of observations can be made from Figures 4a, 4b and 4c. Firstly, evidently a tri-modal distribution of data was apparent in all the parameters except for the TN, which represents di-modal distribution. The plots of fat and DM determined by the tryptophan (Figs. 4a and 4b), vitamin A (data not shown) and riboflavin (data not shown) allowed a good discrimination of cheeses according to their manufacturing processes and cheese composition. In fact, all samples found in the top cluster along the regression line belong to the stabilised cheeses, which had the highest levels of DM $\left(49.57 \mathrm{~g} \cdot 100 \mathrm{~g}^{-1}\right)$ and fat (34.08 g.100 $\left.\mathrm{g}^{-1}\right)$ contents. The bottom cluster, representing the traditional cheeses, allows discrimination between M1 and M 2 cheeses. Indeed, M2 cheeses, which had the lowest fat and DM contents (22.6 g.100 $\mathrm{g}^{-1}$ and $44.45 \mathrm{~g} \cdot 100 \mathrm{~g}^{-1}$, respectively), were located on the bottom along the regression line. Concerning the plot of TN determined from tryptophan fluorescence spectra (Fig. 4c), vitamin A (data not shown) and riboflavin (data not shown), all samples found in the bottom cluster corresponded to the $\mathrm{M} 3$ cheeses, which had the lowest TN content $\left(2.55 \mathrm{~g} \cdot 100 \mathrm{~g}^{-1}\right)$, while those in the top corresponded to the M2 cheeses, which had the highest level of TN (3.33 g.100 g-1).

From the PLS prediction models determined from DM and fat, only a small trend for discrimination between the $\mathrm{E}$ and $\mathrm{C}$ zones was observed between the three cheese varieties using tryptophan fluorescence spectra (Figs. 4a and 4b). The PLS prediction models of TN and WSN from tryptophan fluorescence spectra did not allow this discrimination. The results obtained were a little bit surprising, since tryptophan fluorescence spectra are very sensitive to the molecular structure of the protein network. 

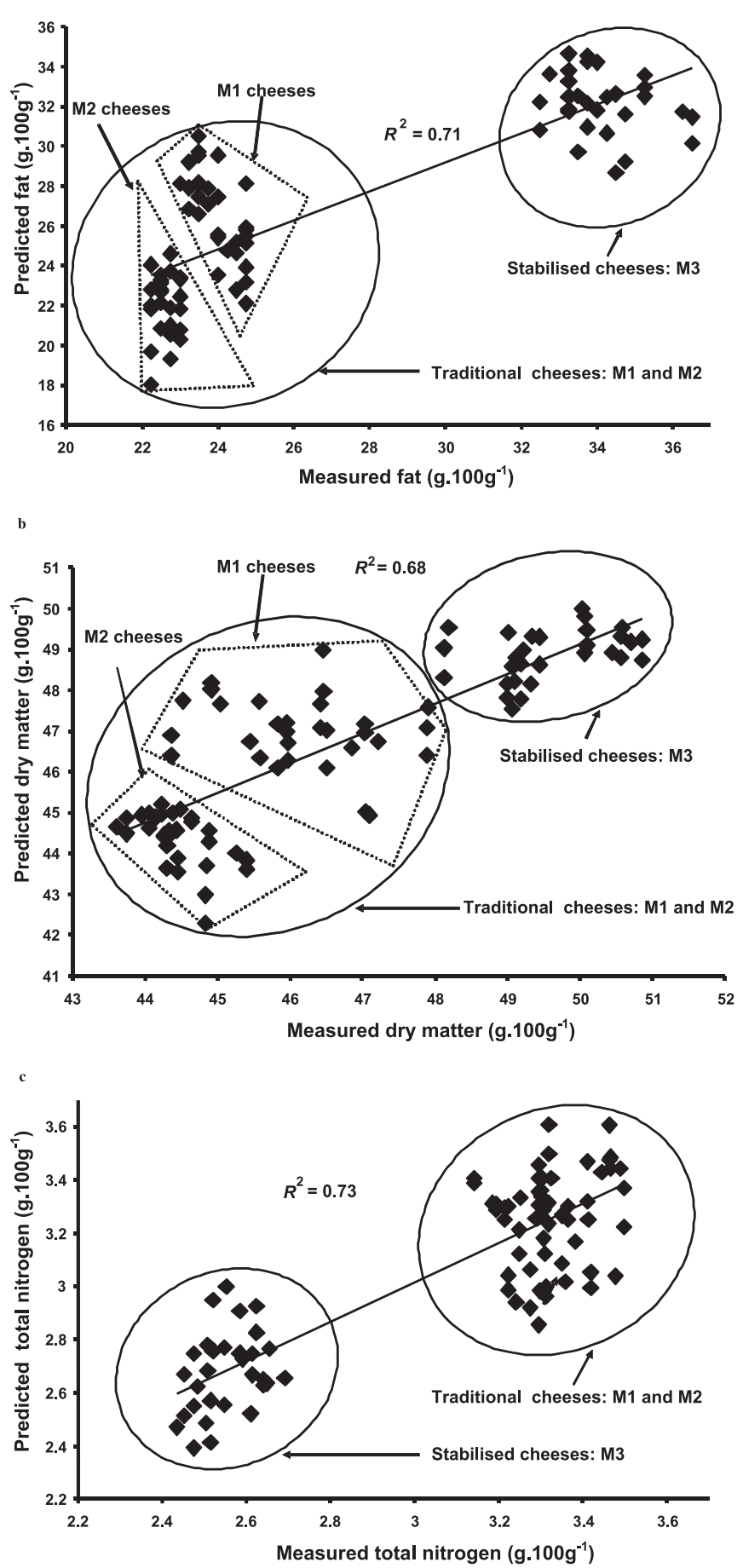

Figure 4. Partial least squares (PLS) prediction models: Actual versus predicted values plots for a cross-validation prediction of a training set of tryptophan fluorescence spectra of fat (a), dry matter (b) and total nitrogen (c). 


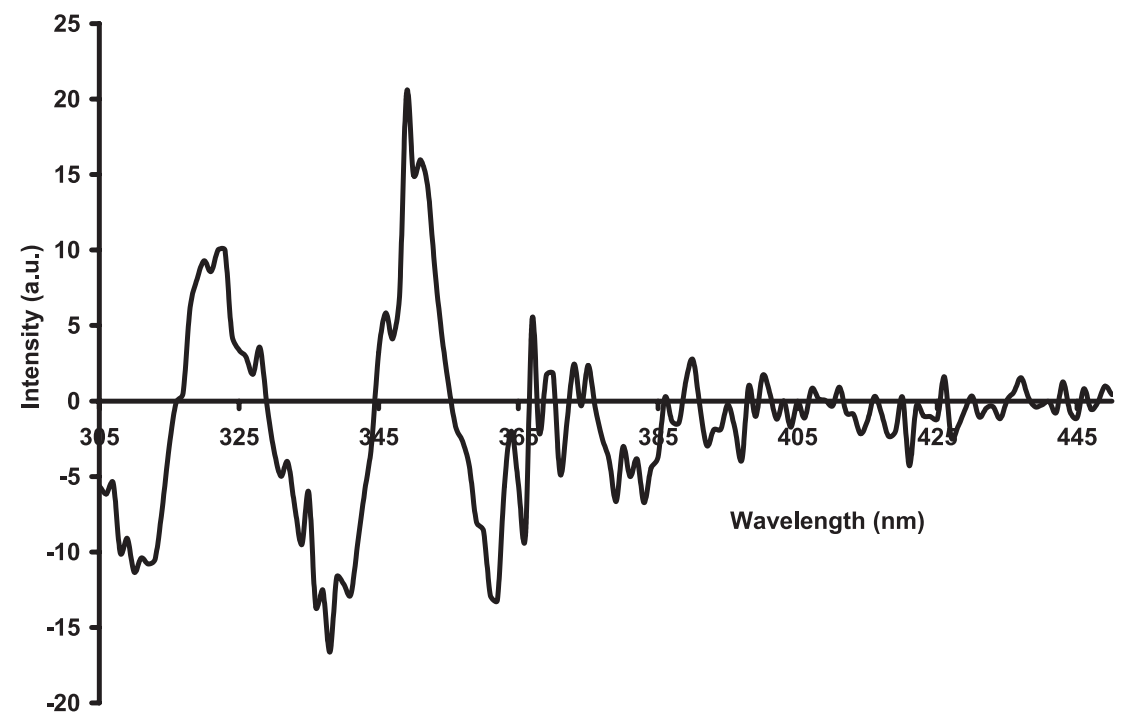

Figure 5. Regression coefficient distribution over the tryptophan fluorescence spectra of watersoluble nitrogen prediction.

One explanation could arise from the small range of the TN and WSN parameters considered in the present investigation compared with those of fat and DM, as shown in Table I. Further research is needed with a great variety of the physico-chemical parameters to test the accuracy of front-face fluorescence spectroscopy for predicting chemical parameters in these cheeses.

To assist the interpretation of the molecular basis for prediction of each of the above parameters, the regression coefficients of the PLS regression models were illustrated. Considering the tryptophan fluorescence spectra, the regression coefficient of WSN is shown in Figure 5, which indicates that 305-360 nm was the most important spectral region. The 370-430 $\mathrm{nm}$ spectral region showed no clear correlation with the WSN. In addition, two peaks located around 350 and $322 \mathrm{~nm}$ were correlated positively, while another peak located at $340 \mathrm{~nm}$ was negatively correlated with the WSN. From this result, it can be concluded that a shift to a higher wavelength was observed when the WSN content increased. This shift in the tryptophan emission spectra indicated that tryptophan residues in protein were in a hydrophilic environment. This phenomenon induced a decrease in the maximum intensity and an increase in the wavelength of the maximum intensity of tryptophan emission spectra. This is in agreement with previous findings reporting that the shape of tryptophan fluorescence spectra changes according to its molecular environment (hydrophilic or hydrophobic). Indeed, it has been reported that the maximum emission of tryptophan fluorescence spectra shifted to a higher wavelength with an increase in the ripening time $[19,34]$. This phenomenon may be related to the partial proteolysis of caseins, which induced an increase in tryptophan residues to the solvent (water). The spectroscopic difference observed in the present findings could also be due to different protein-protein and protein-lipid interactions and different network structures resulting from the ripening time and the manufacturing process. Similar results were obtained with the regression coefficients of fat, TN and DM (data not shown).

The changes observed in the vitamin A regression coefficient of fat are related to 


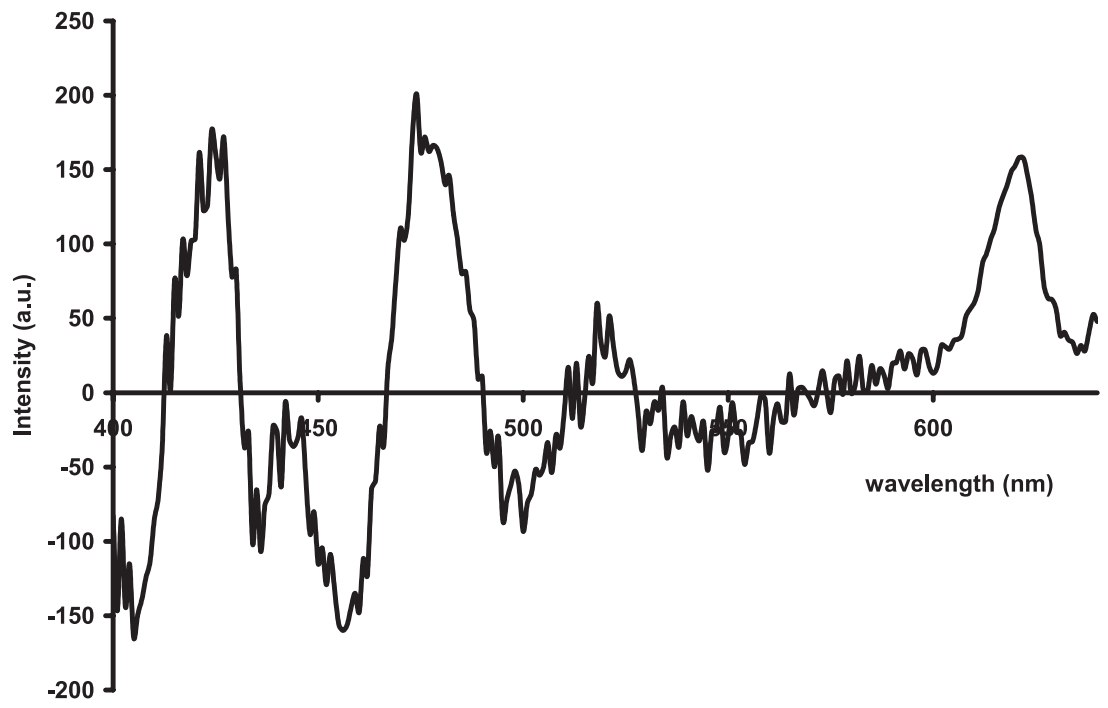

Figure 6. Regression coefficient distribution over the riboflavin fluorescence spectra of fat prediction.

the changes in lipid structure, but interpretation at the molecular level is more difficult (data not shown). Indeed, much less information is available about the relation between the shape of the vitamin A spectra and the organisation of lipids than the shape of the tryptophan spectra and the protein structure. However, it is well known that the fluorescent properties of this fluorophore are very sensitive to changes in the solvent viscosity [19, 22, 23]. Recently, a good correlation between the shapes of the vitamin A fluorescence spectra and the viscosity of lipids in the fat globules have been found [14].

It is clear that considerable structural difference was found in the regression coefficient of fat and that differences existed at the relatively important individual wavelengths or wavelength segments. Indeed, a peak located at $295 \mathrm{~nm}$ was positively correlated with fat, while the peak observed at $322 \mathrm{~nm}$ was correlated negatively. A similar spectral pattern was obtained when the triglycerides in the fat globules of an emulsion model were investigated as a function of the temperature [14].

The regression coefficient distributions of riboflavin fluorescence spectra showed that the wavelengths located at 425,475 , 518 and $622 \mathrm{~nm}$ were correlated positively with fat (Fig. 6), DM and fat in DM, while the bands at 405 and $455 \mathrm{~nm}$ were correlated negatively with these parameters. The regression coefficients of TN and WSN were correlated positively with 404, 434, 456 and $500 \mathrm{~nm}$, while those located at 427 , 475 and $620 \mathrm{~nm}$ were correlated negatively.

From Figure 6, there are several spectral wavelength bands that might be of particular interest. The positive broad peak at about $518 \mathrm{~nm}$ is due to riboflavin, as suggested by Wold et al. [50]. The other region of interest ranges from 600 to $640 \mathrm{~nm}$, within which one peak was observed at $622 \mathrm{~nm}$. This peak has been attributed by Wold et al. [50] to porphyrin and chlorin compounds. The last region between 405 and $480 \mathrm{~nm}$ showed the most important features. The fluorophores responsible for these special bands are not known. This region typically shows fluorescence from stable oxidation products formed by aldehydes and amino acids. In the same region, lumichrome, a photo breakdown product from riboflavin, as well as $\beta$-carotene, exhibits fluorescence in the $400-480 \mathrm{~nm}$ [50]. 


\section{CONCLUSION}

This work demonstrated that it was possible to determine successfully some selected chemical parameters of the soft cheeses investigated taken in the external and central zones using front-face fluorescence spectroscopy coupled with chemometric tools. The results obtained indicated that the vitamin A and riboflavin fluorescence spectra can be used to measure fat, dry matter (DM), fat in dry matter (fat in DM) and water-soluble nitrogen (WSN). However, only the riboflavin fluorescence spectra gave moderately successful calibration for the $\mathrm{pH}$. The prediction of all these parameters using tryptophan fluorescence spectra can be considered as approximate. Only discrimination between high and low concentrations could be satisfied for the WSN/ $\mathrm{TN}$ ratio with the three intrinsic probes.

With only 15 soft cheeses, the current models were still not very robust and further research that should include different varieties of soft cheeses and different ripening times (young, aged and old) is needed. This would allow the inclusion of more variability of the chemical properties and thus the development of general mathematical models for better accuracy of the front-face fluorescence technique. In addition, since the correlation coefficients obtained in this study could be a result of the differences between the stabilised and traditional cheese manufacturing procedures, more research on these soft cheese varieties in the $\mathrm{E}$ and $\mathrm{C}$ zones will be needed to validate the accuracy of the front-face fluorescence technique for the prediction of some selected chemical parameters.

The simplicity of the fluorescence spectroscopy method offers great opportunities for efficient characterisation of cheeses at a very low cost. In addition, fluorescence spectroscopy has the potential of dramatically reducing the analytical time when looking at physico-chemical measurements.

Acknowledgements: We gratefully acknowledge the financial support from the research council of K.U. Leuven.

\section{REFERENCES}

[1] Adamopoulos K.G., Goula A.M., Petropakis H.J., Quality control during processing of Feta cheese-NIR application, J. Food Compos. Anal. 14 (2001) 431-440.

[2] Adams M.J., Latham K., Barnett N.W., Poynton A., Calibration models for determining moisture and fat content of processed cheese using near-infrared spectrometry, J. Sci. Food Agric. 79 (1999) 1232-1236.

[3] Baer R.J., Frank J.F., Loewenstein M., Compositional analysis of nonfat dry milk by using near infrared diffuse reflectance spectroscopy, J. A. O. C. 66 (1983) 858-862.

[4] Baer R.J., Frank J.F., Loewenstein M., Birth G.S., Compositional analysis of whey powders using near infrared diffuse reflectance spectroscopy, J. Food Sci. 48 (1983) 959-961, 989.

[5] Bertrand D., Scotter C.N.G., Application of multivariate analyses to NIR spectra of gelatinized starch, Appl. Spectrosc. 46 (1992) 1420-1425.

[6] Bouton Y., Guyot P., Dasen A., Grappin R., Activité protéolytique de souches de lactobacilles thermophiles isolées de levains et de Comté. II - Applications en sites industriels, Lait 74 (1994) 33-46.

[7] Cattaneo T.M.P., Giardina C., Riva M., Giangiacomo R., Application of FT-NIR and FT-IR spectroscopy to study the shelf-life of Crescenza cheese, Int. Dairy J. 15 (2005) 693-700.

[8] Chen M., Irudayaraj J., Mcmahon D.J., Examination of full fat and reduced fat Cheddar cheese during ripening by Fourier infrared spectroscopy, J. Dairy Sci. 81 (1998) 27912797.

[9] Christensen J., Povlsen V.T., Sørensen J., Application of fluorescence spectroscopy and chemometrics in the evaluation of processed cheese during storage, J. Dairy Sci. 86 (2003) 1101-1107.

[10] Christensen J., Miquel Becker E., Frederiksen C.S., Fluorescence spectroscopy and PARAFAC in the analysis of yogurt, Chemometr. Intell. Lab. 75 (2005) 201-208.

[11] Čurda L., Kukacková O., NIR spectroscopy: a useful tool for rapid monitoring of processed cheeses manufacture, J. Food Eng. 61 (2004) 557-560.

[12] Downey G., Sheehan E., Delahunty C., O'Callaghan D., Guinee T., Howard V., Prediction of maturity and sensory attributes of Cheddar cheese using near-infrared spectroscopy, Int. Dairy J. 15 (2005) 701-709. 
[13] Dufour E., Riaublanc A., Potentiality of spectroscopic methods for the characterisation of dairy products. I. Front-face fluorescence study of raw, heated and homogenised milks, Lait 77 (1997) 657-670.

[14] Dufour E., Lopez C., Riaublanc A., Mouhous Riou N., La spectroscopie de fluorescence frontale : une approche non invasive de la structure et des interactions entre les constituants des aliments, Agoral 10 (1998) 209215.

[15] Dufour E., Karoui R., Bosset J.O., Utilisation de la fluorescence frontale intrinsèque de fromages de type L'Etivaz AOC et Gruyère AOC pour reconnaître leur origine géographique, Trav. Chim. Aliment. Hyg. 94 (2003) 379-393.

[16] Etzion Y., Linker R., Cogan U., Shmulevich I., Determination of protein concentration in raw milk by mid-infrared Fourier Transform infrared/Attenuated total reflectance spectroscopy, J. Dairy Sci. 87 (2004) 2779-2788.

[17] Herbert S., Caractérisation de la structure moléculaire et microscopique de fromages à pâte molle. Analyse multivariée des données structurales en relation avec la texture, Thèse, École Doctorale Chimie Biologie de l'Université de Nantes, France, 1999.

[18] Herbert S., Riaublanc A., Bouchet B., Gallant D.J., Dufour E., Fluorescence spectroscopy investigations of acid-and rennet-induced milk coagulation of milk, J. Dairy Sci. 82 (1999) 2056-2062.

[19] Herbert S., Mouhous Riou N., Devaux M.F., Riaublanc A., Bouchet B., Gallant J.D., Dufour E., Monitoring the identity and the structure of soft cheeses by fluorescence spectroscopy, Lait 80 (2000) 621-634.

[20] Hermida M., Gonzalez J.M., Sanchez M., Rodríguez-Otero J.L., Moisture, solids-nonfat and fat analysis in butter by near infrared spectroscopy, Int. Dairy J. 11 (2001) 93-98.

[21] Izco J.M., Torre P., Barcina Y., Ripening of Ossau-Iraty cheese: determination of free amino acids by RP-HPLC and of total free amino acids by the TNBS method, Food Control 11 (2000) 7-11.

[22] Karoui R., Dufour E., Dynamic testing rheology and fluorescence spectroscopy investigations of surface to centre differences in ripened soft cheeses, Int. Dairy J. 13 (2003) 973-985.

[23] Karoui R., Laguet A., Dufour E., Fluorescence spectroscopy: a tool for the investigation of cheese melting - correlation with rheological characteristics, Lait 83 (2003) 251-264.
[24] Karoui R., Dufour E., Pillonel L., Picque D., Cattenoz T., Bosset J.O., Determining the geographic origin of Emmental cheeses produced during winter and summer using a technique based on the concatenation of MIR and fluorescence spectroscopic data, Eur. Food Res. Technol. 219 (2004) 184-189.

[25] Karoui R., Dufour E., Pillonel L., Picque D., Cattenoz T., Bosset J.O., Fluorescence and infrared spectroscopies: a tool for the determination of the geographic origin of Emmental cheeses manufactured during summer, Lait 84 (2004) 359-374.

[26] Karoui R., Bosset J.O., Mazerolles G., Kulmyrzaev A., Dufour E., Monitoring the geographic origin of both experimental French Jura hard cheeses and Swiss Gruyère and l'Etivaz PDO cheeses using mid-infrared and fluorescence spectroscopies, Int. Dairy J. 15 (2005) 275-286.

[27] Karoui R., Dufour E., Pillonel L., Schaller E., Picque D., Cattenoz T., Bosset J.O., The potential of determination of the geographic origin of Emmental cheeses by combining infrared and fluorescence spectroscopies, Int. Dairy J. 15 (2005) 287-298.

[28] Karoui R., Martin B., Dufour E., Potentiality of front-face fluorescence spectroscopy to determine the geographic origin of milks from Haute-Loire department (France), Lait 85 (2005) 223-236.

[29] Karoui R., Mouazen A.M., Dufour E., Pillonel L., Picque D., Bosset J.O., De Baerdemaeker J., Mid-infrared spectrometry: A tool for the determination of chemical parameters in Emmental cheeses produced during winter, Lait 86 (2006) 83-97.

[30] Kulmyrzaev A., Dufour E., Determination of lactulose and furosine in milk using frontface fluorescence spectroscopy, Lait 82 (2002) 725-735.

[31] Kulmyrzaev A., Dufour E., Noël Y., Hannafi M., Karoui R., Qannari E.M., Mazerolles G., Investigation at the molecular level of soft cheese quality and ripening by infrared and fluorescence spectroscopies and chemometrics-relations with rheology properties, Int. Dairy J. 15 (2005) 669-678.

[32] Laporte M.F., Martel R., Paquin P., The nearinfrared optic probe for monitoring rennet coagulation in cow's milk, Int. Dairy J. 8 (1998) 659-666.

[33] Mazerolles G., Duboz G., Hugot S., Détermination du taux d'humidité et de matière grasse de fromages de type pâte pressée par spectroscopie proche infrarouge en mode transmission, Lait 80 (2000) 371-379. 
[34] Mazerolles G., Devaux M.F., Duboz G., Duployer M.H., Mouhous Riou N., Dufour E., Infrared and fluorescence spectroscopy for monitoring protein structure and interaction changes during cheese ripening, Lait 81 (2001) 509-527.

[35] Mazerolles G., Devaux M.F., Dufour E., Qannari E.M., Courcoux Ph., Chemometric methods for the coupling of spectroscopic techniques and for the extraction of the relevant information contained in the spectral data tables, Chemometr. Intell. Lab. 63 (2002) 57-68.

[36] Mc Queen D.H., Wilson R., Kinnunen A., Jensen E.P., Comparison of two infrared spectroscopic methods for cheese analysis, Talanta 42 (1995) 2007-2015.

[37] Miquel Becker E., Christensen J., Frederiksen C.S., Haugaard V.K., Front-face fluorescence spectroscopy and chemometrics in analysis of yogurt: rapid analysis of riboflavin, J. Dairy Sci. 86 (2003) 2508-2515.

[38] Mortensen G., Sørensen J., Danielsen B., Stapelfeldt $H .$, Effect of specific wavelengths on light-induced quality changes in Havarti cheese, J. Dairy Res. 70 (2003) 413-421.

[39] Mortensen G., Sørensen J., Stapelfeldt H., Effect of modified atmosphere packaging and storage conditions on photooxidation of sliced Havarti cheese, Eur. Food Res. Technol. 216 (2003) 57-62.

[40] Mouazen A.M., De Baerdemaeker J., Ramon H., Towards development of on-line soil moisture content sensor using a fibre-type NIR spectrophotometer, Soil. Till. Res. 80 (2005) 171-183

[41] O'Callaghan D.J., O'Donnell C.P., Payne F.A., On-line sensing techniques for coagulum setting in renneted milks, Int. Dairy J. 43 (2000) 155-165.
[42] Sørensen L.K., Jepsen R., Assessment of sensory properties of cheese by near infrared spectroscopy, Int. Dairy J. 8 (1998) 863-871.

[43] Spellman D., McEvoy E., O'Cuinn G., FitzGerald R.J., proteinases and exopeptidase hydrolysis of whey protein: comparison of the TNBS, OPA and $\mathrm{pH}$ stat methods for quantification of degree of hydrolysis, Int. Dairy J. 13 (2003) 447-453.

[44] Strasburg G.M., Ludescher R.D., Theory and application of fluorescence spectroscopy in food research, Trends Food Sci. Technol. 6 (1995) 69-75.

[45] Wehling R.L., Pierce M.M., Determination of moisture in cheddar cheese by near infrared reflectance spectroscopy, J. Assoc. Off. Anal. Chem. 71 (1988) 571-574.

[46] Williams P.C., Variables affecting near infrared reflectance spectroscopic analysis, in: Williams P., Norris K. (Eds.), Near infrared technology in the agricultural and food industries, St. Paul, AACC, 1987, pp. 143-167.

[47] Williams P.C., Near-Infrared Technology Getting the Best out of Light, PDK Grain, Nanaimo, Canada, 2003.

[48] Wittrup C., Nørgaard L., Rapid near infrared spectroscopic screening of chemical parameters in semi-hard cheese using chemometrics, J. Dairy Sci. 81 (1998) 1803-1809.

[49] Wold J.P., Jørgensen K., Lundby F., Nondestructive measurement of light-induced oxidation in dairy products by fluorescence spectroscopy and imaging, J. Dairy Sci. 85 (2002) 1693-1704

[50] Wold J.P., Veberg A., Nilsen A., Iani V., Juzenas P., Moan J., The role of naturally occurring chlorophyll and porphyrins in light-induced oxidation of dairy products. A study based on fluorescence spectroscopy and sensory analysis, Int. Dairy J. 15 (2005) 343-353. 